\title{
New technology in urban transport
}

\author{
C. G. B. MITCHELL
}

\section{Mr W. P. Winston, Freeman, Fox \& Partners}

When one attempts to plan or design a system incorporating one of the new technologies it is suggested that a number of points arise. For instance, in $\S 26(b)$ the Author suggests that unmanned operation permits provision of a 24 hour service. This may be so at an airport in the sense that the 24 hour demand of the airport can be met. In urban areas it is suggested that providing a 24 hour service may entail providing additional capacity to permit track and control equipment to be taken out of service for maintenance. Surely in many instances the cost of providing this extra capacity will not be acceptable? May not closure from time to time therefore have to be accepted?

61. In $\S 29$ the Author suggests that what will make minitrams and network cabs viable in cities is that $90^{\circ}$ bends in track can be put into a radius as small as $7 \mathrm{~m}$. This postulates a speed of less than $15 \mathrm{~km} / \mathrm{h}$ if the acceleration is to be acceptable. This is little more than twice walking speed. Presumably such a system would have a low capacity. In $\S 34$, speeds in the range of $30-50 \mathrm{~km} / \mathrm{h}$ are mentioned for network cabs and in $\S 41$ a speed of $100 \mathrm{~km} / \mathrm{h}$ is mentioned. The conclusion is that this technology can provide a very wide range of speeds. In $\$ \$ 44$ and 45 the results of some studies of network cab and dual-mode systems are given. In the circumstances, would the Author indicate the speeds used in these studies, especially on the segregated tracks? In the instances of turnouts and intersections was grade separation assumed?

62. In Table 2, minimum headways are given for systems. It is suggested that in a practical system it will be necessary to consider also the maximum headway. For conventional transport systems the practice is to publish the operational headways unless very short and, if they are significantly large, to operate the service to a timetable which is published. For the Underground system in central London these headways are published and also the travelling times between stations. Thus between Victoria Station and Paddington Station at certain times of day the maximum total headway is $11 \frac{1}{2}$ minutes compared with a train journey of 10 minutes. In the case of a system designed to operate automatically on a demand basis, a surveillance system is required to govern headway, that is, the maximum time a passenger has to wait for a vehicle, since it is a parameter which defines the level of service. Automation of this surveillance process appears to require would-be passengers to register a travel demand at a station. In the case of network systems this appears likely to require everybody to queue in peak periods. In the case of a line haul system off peak, apparently the passenger has to be prepared to accept a wait equal to the headway. These appear to be rather severe disadvantages unless systems are designed or operated to mitigate them, which would increase capital or operating costs.

63. In $\$ 57$ the Author points out that segregated transport systems will permit extensive pedestrianization. Pedestrianization schemes are currently popular but extensive schemes attract a certain amount of criticism. One problem is to provide a sufficient number of pedestrian and transport interchange points, namely, stations. The Author deals with this problem from the point of view of block speed. Fig. 6(a) suggests that the minimum station spacing to give an acceptable station to station speed is, say, $0.5 \mathrm{~km}$. This postulates a minimum line spacing of $0.5 \mathrm{~km}$. It does not follow that such close spacing will be justified or feasible. Thus if the sole means of transport is one of the new network or line haul systems, in principle pedestrianized

Paper published: Proc. Instn Civ. Engrs, 1972, 52, Aug., 127-147. 
areas will be $0.5 \mathrm{~km}$ square or upwards in size. A pedestrianized area $0.5 \mathrm{~km}$ square may be acceptable; the larger areas may well be found deficient in transport at least for some pedestrians or classes of pedestrian trip, such as shopping. The situation may be aggravated if the area is hilly. In large pedestrian schemes a tentative solution is to use some other new technology, such as a moving pavement, to 'shrink' the area in terms of walking time and physical effort. In this connexion, it is perhaps not irrelevant to recall that before lifts were common in hotels, room charges tended to decrease with height. A similar situation may arise in large pedestrianized areas if transportation is inadequate.

64. When evaluating the application of the new technologies it is suggested that it will be useful to consider what is an appropriate minimum journey or vehicle speed to make a system attractive. This speed may well be found to vary with the application. For instance, in an airport, a lower speed may be acceptable in comparison with a city centre.

65. It is suggested that studies of new systems should include the automation of ticket issuing and enforcement since ticket systems affect station design, manning and door to door journey time. For short trips, e.g. on moving pavements and escalators, it is not usual to make a charge but on some public lifts a charge is made. For the present it appears unlikely to be feasible to plan for entirely free transport.

\section{Mr W. A. H. Hamilton, $M$}

If I understand the Author correctly, minicabs are a practical proposition only within areas of high density and high activity. I should be interested to know where in fact he thinks minicabs should be installed and who will use them.

67. I think that elevated track would be totally unacceptable in London or anywhere else not built from scratch for such a system. The Author shows a photomontage of cab track in Victoria Street, but what would happen at Westminster Abbey or Parliament Square? I suspect a tangled mass of lines in every direction permanently scarring the scene. I feel that minicabs will have to be operated for much of their routes at or below ground level if they are to be environmentally acceptable.

68. As to who will use them, I doubt if they will be more attractive than private cars, unless the latter are taxed or legislated off central streets. However, if this were the case, one is led to believe by bus companies and Fig. 3 that congestion would disappear from the streets and that buses and conventional taxis would be able to operate efficiently, economically and quickly, thereby making the minicabs unnecessary. Does the Author accept this view? If they could substitute for both cars and buses I think that it should be feasible to bring the minicabs down to ground level. Has the Author studied the practical and technical implications of attempting to mix minicabs and a residue of conventional road vehicles?

\section{Dr Mitchell}

The speeds necessary for a minitram or network cab system to provide an appreciably better service than existing cars and buses are approximately $35 \mathrm{~km} / \mathrm{h}$ in the city centre and $50-60 \mathrm{~km} / \mathrm{h}$ in the suburbs. A minimum radius of about $40 \mathrm{~m}$ is required for $35 \mathrm{~km} / \mathrm{h}$ running to keep the lateral acceleration below $0.25 \mathrm{~g}$ for seated passengers, or of $100 \mathrm{~m}$ to keep the acceleration below $0.1 \mathrm{~g}$ for standing passengers. Studies of routes for elevated systems in city centres suggest that a minimum radius of $40 \mathrm{~m}$ can be achieved for main lines, but that smaller radii, down to perhaps $7 \mathrm{~m}$, are needed in some stations and junctions. These tracks would have to be traversed at reduced speed.

70. Small-vehicle systems, whether network cab or minitram, give better passenger service than conventional rail or bus systems. The frequency of a minitram system is much higher than that of conventional systems, and the network cabs give service on demand. This much reduces waiting time off-peak and, by providing a more continuous flow of passengers, should reduce queueing and congestion during the 
peaks. By reducing minitram trains to single vehicles off-peak the maximum service interval can be kept to a few minutes without the cost of running many vehicle miles at low loads.

71. Both minitram and network cab systems are cable of providing 24 hour service, but naturally links will need to be closed from time to time for maintenance. A network cab system has sufficient redundancy to allow diversion of vehicles round a closed link. A mintram system would either have to rely on single-line running or to provide an alternative bus service during maintenance. The problem of track maintenance exists now for both road and rail based transport systems, and today's solutions will also apply to the novel systems.

72. The extent to which elevated systems will be permitted in cities in the UK is not yet known. Advanced Systems Division, Transport and Road Research Laboratory, has already commissioned a great deal of work to determine the visual and acoustic effects of such systems, and more work is in progress on elevated track, track in shallow tunnels and track in cuttings. However, the decision as to whether these effects are acceptable is a value judgement that will ultimately be made by city councils and planning staffs, not by scientists or engineers. In the USA it has been made in favour of elevated routing in Morgantown for a minitram system and in parts of San Francisco and Chicago for heavy rail systems.

73. Advanced Systems Division has already studied hypothetical minitram, network cab and rail systems in the West Midlands conurbation, and has found that minitrams give the best service for a given cost, and that the track could extend well into the suburbs. Studies of other cities are now being made, but on the basis of trip densities I would expect most cities of more than about 400000 population to be able to justify a minitram system.

74. The prospect of mixing automatic and manually controlled vehicles is frightening and, with one exception, unlikely to occur. The exception is a low speed, ground level vehicle system for pedestrian precincts, to provide a finer grid of service than is practicable with a minitram. At speeds of up to about $8 \mathrm{~km} / \mathrm{h}$ such a vehicle could stop in $1 \mathrm{~m}$, and could be designed to detect obstructions and pedestrians at a slightly greater distance than this.

75. My main reasons for believing that novel tracked public transport systems will come into being, whether in tunnel or elevated, are that

(a) they provide better service at lower capital cost

(b) they much reduce the need for staff to work unpopular shift hours

(c) the cost of equipment is steadily reducing, relative to that of labour

(d) cars have shown the benefits of individual transport to the user, but there is not space in cities for a wholly car based transport system. 